\title{
Negotiation Strategy to Achieve a Win-Win Result within Oligopolies
}

\author{
Wenbin Wan'1, Yuxin Jin², Yijia Sui ${ }^{3}$ \\ ${ }^{1}$ Big Bridge Academic, Wuxi, China \\ ${ }^{2}$ Chengdu Shude High School International Department, Chengdu, China \\ ${ }^{3}$ Stoneleigh Burnham School, Massachusetts, USA \\ Email: wanwenb@icloud.com
}

How to cite this paper: Wan, W.B., Jin, Y.X. and Sui, Y.J. (2019) Negotiation Strategy to Achieve a Win-Win Result within Oligopolies. American Journal of Industrial and Business Management, 9, 2144-2155. https://doi.org/10.4236/ajibm.2019.912142

Received: October 10, 2019

Accepted: December 14, 2019

Published: December 17, 2019

Copyright $\odot 2019$ by author(s) and Scientific Research Publishing Inc. This work is licensed under the Creative Commons Attribution International License (CC BY 4.0).

http://creativecommons.org/licenses/by/4.0/

\begin{abstract}
Being a businessman in the modern life, globalizing has become a potential issue to consider when having business with foreign companies. To make the business easier by keeping the ideal profit and reduce the internal loss, communications has become a bridge toward mutual success. In the article, we focused the object into the oligopolies, since they are the main groups involved into the international business: for smaller firms, they have little chance to have involvement with the foreign companies; while for monopolies, they do have too much weight to influence the whole market. So the oligopolies are the best objects to study since they each has a kind of influence but no one can have the dominating right, which means they all depended on each other. And we conclude the situations into three main situations-Supply Chain, Litigation, and Mergers and Acquisitions. In other situations, companies can also use some of the strategies mentioned in the passage and should be managed specifically. We found several typical cases and had deeper analyze about these conditions. Depending on examples of these well-known companies and events, we got some interesting and common factors that they all need deeper knowledge about each other. While the communication is a tool to maximize their profit depending on their power and to reduce the cost and risk. Our group finally came up with two strategies for each of the situation, and all of us hold the opinion that enough knowledge of both companies is quite necessary. Though applied to a different formula, such as making comparation, or hiring competent advisors, or making official meetings, each form needs the baseline of both companies. Then it will be much more convenient to achieve the mutual gain. The money spent on the researches can greatly improve the efficacy by reducing the implicit cost.
\end{abstract}




\section{Keywords}

Negotiation Strategies, Oligopolies, Supply Chain, Mutual Gain, Litigation, Competitive Advantages, Mergers and Acquisitions (M \& A), Fundamental Goals

\section{Introduction}

Works by (Chakrabarti, 2010) [1] have studied operating loss for the oligopolies when they are acting the non-communication strategy and the efficiency for the communication. The tit-for-tat strategy is doing harm for both of the companies. When the firms both receive a sign of others, they will have the result action and finally reduce the resulting profit if they do not have communication. Firms will collude if they agree either tacitly or explicitly to produce one potential output. So, it is very necessary to find an efficient communication strategy to reduce any kind of loss, both explicit and implicit. "By the application of cooperative game theory to oligopoly, we have been able to show in this paper that the incentive to form coalitions is a function of market's 'ethos"” (Rajan, 1989) [2], the idea is similar to the conclusion made by Chakrabarti, "there is strong incentive for the firms to collude". Negotiation is a process of mutual discussion and arrangement of the terms of a transaction or agreement. Negotiation exists mostly to maximize both sides' benefits and interests, which is to result in a win-win situation. In a work done by (Phelps, 1942) [3], the author mentioned that if the market has one successful result, it could be standardized as the formal communication strategy to cooperate. And negotiation strategies under three different situations will be discussed below, and every situation will be illustrated by the examples of companies from an oligopoly market, which refers to the market condition when there are few sellers, as a result of which they can greatly influence price and other market factors. The first situation is the supply chain, which means marketing a channel of distribution beginning with the supplier of materials or components, extending through a manufacturing process to the distributor and retailer, and ultimately to the consumer. And examples of Walmart and P \& G will be used. In this situation, they need to get a formal agreement of their future trade. Secondly, in the situation of litigation, which refers to the act or process of litigating, examples of Samsung and Huawei will be used to explore the negotiation strategies. In litigation, firms are usually involved with the disagreement with the use of patent, or Standard-Essential Patent (SEPs) (Randakevičiūtè, 2015) [4] and those high-tech companies need to deal with the issue frequently. For example, (Tsilikas, 2019) [5] \& (Li, 2018) [6] have studied the litigations for Huawei and Samsung with other huge Internet or high-tech companies in the Europeans and in China. The last one is Merge and Acquisition which refers to the integration of two or more businesses to form a single company. And the examples of Cadbury and Kraft will be employed. 
There are some universal strategies to deal with most of the situations: The companies should analyze the market condition for each other to have a clearer understanding of the other party, avoiding conflicts. For instance, having a thorough understanding and comprehension of the company's cultures and its country's cultures are extremely significant, in that case, the companies have the least probability to cause conflicts derived from their frictions in the different manners and thinking modes due to different cultures. For example, some countries like China may consider giving gifts to be indispensable to for the sake of building good relationships while others like the United States consider it to be illegal or immoral. While facing specific cases, firms need more related communication strategies to make both companies beneficial. In reality, universal strategies cannot fully solve the problem; companies need point-to-point actions to protect their profit. Thus, in this research paper, the research question is: What negotiation strategies can a company within an oligopoly use in 1) supply chain; 2) litigation; and 3) mergers and acquisitions (short for $M \&$ A) contexts to achieve a win-win result?

\section{Supply Chain}

\subsection{Seeking Mutual Gain through Negotiation}

For the supply chain, the first strategy for business use to negotiate is to seek for mutual gain with the supplier. If the business can spend time to find out the supplier's goals, it is more likely that the business can find more mutual benefits with the supplier in the negotiation. Making profits as much as possible is definitely the most important mutual goal for either side, but if the supplier does not compromise on price, perhaps, other areas of the agreement are negotiable, say, the amount of deposits, the discount for purchasing more than previously promised and other areas of interest that might yield greater benefits for both parties. During the negotiation, the company should try to focus on finding the other areas mentioned above to seek mutual benefits. A case in point is Walmart vs. P \& G. Walmart is the world's largest retailer. It sold $\$ 482.1$ billion worth of goods in 2016 (Negotiation Experts, 2019) [7]. It aims to provide quality products at a low price. Being a supplier with Walmart, the retailer giant could be regarded as a warrant for long-term profitability. P \& G executive Tom Muccio started a new supplier-retailer partnership between P \& G and Walmart in 1987. Instead of providing products with even lower prices, $P \& \mathrm{G}$ chose to do other things to benefit both parties in the partnership with Walmart. It relocated its company to be near to Walmart's base in Arkansas; it cultivated mutual trust with Walmart by signing Letters of Intent instead of complicated legal contracts. By focusing on problem-solving and information sharing, P \& G and Walmart had found more mutual goals that benefit both parties. From 1987, when Muccio first made these changes, to 2003, P \& G's sales to Walmart grew from $\$ 350$ million to $\$ 7.8$ billion. Another successful supplier of Walmart who had applied the same strategy of focusing on mutual benefits is Frey Farms that managed to 
enter a co-management agreement with Walmart to the effect that "Frey Farms could share the responsibility of managing inventory levels and sales and ultimately save customers money while improving their own margins" (Negotiation Experts, 2019) [7].

\subsection{Persuading Suppliers into Believing It Is the Best Business Partner}

Secondly, the business should persuade the supplier into believing or help the supplier to understand that the business is the best customer of choice for the goods and services. The better suppliers know that the business is a long-term business partner with very robust profitability, the more likely they are to enter a partnership with us even at some affordable expense of its profits. Of course, the company in negotiation can resort to statistics-its revenues, its net profits, its market share, its sales and the profits it has been bringing to other suppliers-suppose the company has diverse suppliers-to talk its suppliers into believing that it has strong ability to bring sustainable and enormous return for its business partner. In this process, the company should also know the profitability of the suppliers to make sure its offer is attractive enough for the supplier engaged in the negotiation and how much discretion it has before it hits the bottom line of the supplier. However, the company can also achieve the same goal by either bluffing or matter-of-fact confessing, to the other party that it has alternatives-other rival suppliers as bidders, and if they do not do business with the company, it will go for someone else. This way, the company can usually get better pricing and have contractual terms in its favor (Harroch, 2016) [8]. Take Amazon, a well-known online retailer based in America. In 2014, Amazon made several agreements with Hachette and Warner. It stopped preordering for books published by Hachette and Warner Home Video products. Amazon is using its dominant role in selling products to get huge concessions from suppliers. Expectedly, the strategy works. "Amazon effectively gets a 53 percent discount on all Random House titles. Kindle e-books account for a fifth of the entire U.S. book market" (Kim, 2017) [9]. Amazon wins in its negotiation with its suppliers because Amazon diversifies its suppliers and let them know they are totally replaceable. Also, it shows its suppliers that it is the best business partner they can have because of its excellent profitability and great potential for sustainable growth. Any publisher understands that even though they want Amazon to pay them more and Amazon wants to pay them less, it is worthwhile for them to sacrifice a small portion of their profits to obtain even more in a long run.

\section{Litigation}

The second situation a company will most likely to face while having a business is litigation. The litigations a company has to deal with can be mainly divided into two types. The first one is the litigation of products and services between the company and the consumers. The second type is the litigation of patents 
between two companies. As the first type mainly depends on the system and the ability of the CEO, which will not mention it in the following paragraph. The passage will mainly focus on the litigation between two companies struggling about patents. And high-tech companies are often involved with this type of problems. Huawei and Samsung are not recent involved with the litigation about patents. It has been a long-lasting problem. (Li, 2018) [6] focused on the litigation between Huawei vs. InterDigital. And (Tsilikas, 2019) [5] focused on Samsung in the European region. Both of them focus on the 3-G technology. (Randakevičiùte, 2015) [4] had a study of both companies with different samples. So the litigation is quite frequent among the technology companies.

While having litigations between companies about two companies, there are two strategies which two special companies use to help get through the litigation:

First, though the litigation Huawei stated the competitive advantages of its company and the disadvantages of the opposite company to show that they can both be better with the stop of the litigation.

Second, Samsung mentioned that endless litigation would only be a loss for both companies without absolute power and it is impossible to win the litigation without great payoff.

\subsection{Identify the Competitive Advantages and Disadvantages for Both Companies}

The most recent and successful example of litigations between companies is the settle of a dispute over the smartphone patents between Huawei and Samsung. Huawei first has litigation with Samsung on the patent of the LTE technology of the $4 \mathrm{G}$ mobile phone since 2011 (Jiang, 2019) [10]. In 2018, Huawei wins the litigation in China for the first time and Samsung needs to pay Huawei 80 million for the patent. But the America government did not agree with the result of the litigation and try to influence the result. At the end of 2018, Huawei and Samsung compete for the first publication of the $5 \mathrm{G}$ folding screen mobile phone. They have some cooperation with the new technology. Then not surprisingly in May of 2019, Huawei and Samsung finally have an agreement to share their patents and cooperate in the future mobile market (Doug, 2019) [11]. According to the steps of the relationship, researchers can deeply analyze the strategy they use to end the harmful litigation to both beneficial results.

After years of researching and having litigations of each other, companies have been aware of the advantages and disadvantages for each other. The founding father of modern economy Adam Smith mentioned in his book that human usually does not have a great difference in talent, they can finally focus on a certain part, thus, by the influence of the hidden hand, the industry will maximize its productivity and efficacy. This will be the same as the firms. In the beginning, they do not know each other. Without litigation, they do not know clearly about the advantages and disadvantages. Just like a required step for the oligopoly companies to know each other, they have to learn more about the true 
power of each other and know that their levels are matched. Companies will not devote much of the time self-realizing or studying about the competitive company until some great problem happened to appear among these two. Of different cultures, Huawei and Samsung do not know that much about each other. They need a period for each other to know the clear culture and power. To end the litigation, the defendant needs to collect enough data and come up with the competitive advantages and disadvantages of each other. Thus, there will have both beneficial results if they stop the litigation or even start cooperation. Just like the basic knowledge of economy-the trade can improve productivity through the difference of productivity. During the litigation, Huawei can Samsung fond the advantages and disadvantages of each other:

Advantages

Huawei

1) Have a huge number of Chinese consumers.

2) Experienced in the building of base stations.

3) $4 \mathrm{G}$ mobile patent.

4) Chinese government support during the litigation.

Samsung

1) National fame (more popular).

2) Strong technology of the mobile phone.

3) Have the core technology of the $5 \mathrm{~g}$ system.

\section{Disadvantages}

Huawei

1) Operating as a symbol for China, Huawei faces a lot of difficulties abroad.

2) Lack of market share all over the world. Huawei has no technology advance to get the market.

Samsung

1) Be regarded as the second government of South Korea. The litigation of Samsung in China will have little chance to win in the long term.

1) Samsung has an advantage in technology service and transfers but not good in the base infrastructures.

2) Do not have good fame in China.

Huawei and Samsung found that

1) Huawei and Samsung can share Samsung's national fame, and Samsung can have a larger market in China.

2) Represent cooperation of South Korea and China.

3) Share the profit by sharing the patent.

4) Stop wasting time and money.

5) With the cooperation on the investment of folding screen mobiles and the 5 g technology.

6) The technology of both companies can be improved, the can be more competitive in the phone market.

7) They can know each other better. 


\subsection{Preventing Substantial Losses by Ending Litigation Swiftly}

Knowing that each company has competitive advantages and disadvantages, they may realize that it is not wise to continue the litigation. But then two points come. The first is that if one company starts to declare the willing of ending the litigation, it will face the probability of losing face or be regarded as weak by others. This will lose the fame over the world. The second problem is that a cooperate may be regarded a "Trust". They cannot have formal cooperation so the result can only be in the form of the litigation. Thus, the litigation is the form or process to achieve the win-win result. To all the companies, litigation is not what they want. What they want is the profit gained by the action. The CEOs may have secret meetings and negotiating about the requirements. And be shown to the public as the form of litigation. Once they achieve an agreement, the litigation will end swiftly. Reduce the sub-cost led by the arguement of distribution of profit.

\section{M \& A}

One of the most common types of negotiation between companies to achieve agreements is about merger and acquisition. Besides those normal and universal strategies mentioned above that companies should utilize to deal with each other in all types of negotiation, some other specific and particular strategies should be considered in the process of negotiations between companies' merger and acquisition. And the three most significant strategies that companies can use will be illustrated by the examples of M\&A between two multinational oligopoly companies in the food industry.

One company is called Kraft Foods (Kraft, 2018). Kraft is a big American food limited company which is set up in 1924s. At present, it has already become the second-largest food company worldwide. The other one is called Cadbury Schweppes (Cadbury, 2018) [12]. Cadbury is a big British food limited company which is set up in 1824s and has a long history, thus having a stable good reputation for a long time. Also, it's been the second-largest candy company worldwide now. These two companies sell their products across different companies and are counted as two of the oligopolistic companies in the food industry. These two companies had begun to negotiate to form M \& A since September 2009. And didn't achieve an agreement until February 2010 (Cadbury, 2018) [12].

\subsection{Identifying Fundamental Goals}

The first vital strategy in such cases for companies is to identify their fundamental goals at the outset to have a clearer understanding of the benefits which can be brought to both sides. To set a good and specific goal, necessary information, including each company's cultures, demands, abilities, and uniqueness, is indispensable to know about. For example, in the case of Kraft and Cadbury, they have very similar company cultures and country cultures-both attach importance to "respect, integrity, and quality". Also, they have a very similar status in 
the food industry: one is the second-largest food company while the other is the second-largest candy company worldwide. Therefore, the integration of both companies would cast significant influences on the whole food industry and affect the status of the largest food company in the world-Mars. Therefore, seen from this information, we can know the goals of Kraft and Cadbury's integration can be gaining economies of scale so as to exceed the world's largest company, which mean that the integration of them can decrease the average cost of each product produced by taking advantages of each other from the aspects of labor force, experience of both companies' expansion, marketing values, and technology, etc.

\subsection{Considering Ways to Set an Appropriate Price}

Indispensable strategies are necessary to set the right price. Firstly, hiring competent advisors can be practical to address sensitive matters. Some companies may fail to achieve an agreement in negotiations just due to their neglect of hiring an experienced advisor. Such kind of advisor can provide plausible suggestions in negotiation processes for companies by their expertise and rich experiences and they would be more professional than most businessmen about the issues of finance and legality, providing companies with preponderances. After clearly identifying the goals of the whole negotiation between both companies, the most important step is to set an appropriate price of the acquisition. Hiring an advisor can also show the company's efforts and sincerity at the conscientious cast on the negotiation. This action can not only show the transparent and informed decision-making process, decreasing the probability of conflicts but also show the company's expertise and attached great significance. At the beginning of the two companies' negotiation in September 2009 (Cadbury, 2018) [12], Kraft posted 10.3 billion pounds for the sake of taking over Cadbury, but Cadbury directly refused due to this low price. The second strategy is to set a price according to its competitors' actions. During the meantime, the competition of taking over Cadbury became very intense due to its good reputation and products: Hershey company even tried to pose 17 billion pounds to do this, as well as Nestle's proactive actions. At this time, companies use frequent strategies to negotiate, trying to show their unique benefits that can bring to Cadbury. In December, 2009, conflicts happened between Kraft and Cadbury as Cadbury slammed the hostile takeover inclination of Kraft by low price posted and even called for other companies' opposition to Kraft's acquisition, bringing negative impacts to Kraft's reputation. Then both sides employ avoidance to deal with this conflict and wait for its disappearance by just ignoring it. Eventually, in February 2010, BOD of Kraft claimed that they accepted Cadbury's acquisition price-11.7 billion pounds and successfully took over Cadbury. From the process of negotiation between Kraft and Cadbury, we can see the important role that price played in M\&A negotiations. To gain a preponderance, it's extremely important to set an appropriate price. If not, like what happened between Kraft and 
Cadbury in December, 2009, conflicts may be caused unexpectedly and bring negative impacts to either side.

\section{Similarities between the Successful Cases}

While analyzing the three recent-year events, we have no surprise found that these successful events have several points in common. Before they eventually made an agreement, they have a fully understanding of the other firms, and they have different base-lines and expected situation. However, they achieve this situation with different costs. For example, Huawei \& Samsung used nearly 10 years to fully understand each other before finally end the litigation to share the patents. This is really an expensive cost for any kind of company. But once after they finally ended the litigation and made the share of patent, the influence of both companies had come to a larger scale. Moreover, in any conditions, the companies want to prove that they are the best chance for each other. Like the Supply Chain, with a generally low price and large market share by the large numbers of the consumer, the other media companies are willing to prove their long-term cooperation to achieve profit for both companies. In the end, after learning all the required information, and showing certificates of reliability and power, the important thing is to make the agreement. In M \& A, Kraft had been rejected several times due to the price did not match the Cadbury's requirements. They finally hired some competent advisors to help made the final price setting which satisfied the needs and baseline for both of the companies.

In these three successful cases our study mentioned, the strategies do not mean to be exclusive. In any kind of conditions, we need to use almost all of the strategies. But the different condition means different focus for these events. Each category has better solutions if we focus more on these strategies.

\section{Conclusions}

Communications are quite useful tools for the companies to avoid the loss of profit in the competition (Chakrabarti, 2010). The supply chain and the retailers are playing an important part for most of the product-based companies. And most of the time, it will be a long-term relationship for both of the firms. As mentioned in the passage, setting an eclectic price which is comfortable for both of the firms and to make others believe that it is the most reliable choice and be a potential reduce in cost that the products can be transported and sailed in time and avoid the long time in finding proper cooperators; for the litigations, there may be many results. Usually, after the litigation, one company will pay a lot for another company depending on the result of the litigation. Actually, the best result is quite rare but will make a lot of profit for both of the companies. In litigation, both of the firms need to end the litigation as soon as possible if they have competitive or absolute advantages. These are signs for the possibility of cooperation. This will even make both companies more competitive according to litigation event between Huawei and Samsung which successfully maximize the com- 
petition power for both companies after the agreement of ending the litigation in 2019; for M \& A, the time and the price are quite important. The value should be a little bit higher than the holder's baseline but also lower than the future gain. And for the buyer, the trade should be signed as soon as possible to avoid any increase by the other competitors.

Time and information are two keys for the win-win situation by reducing the implicit cost. To get the highest efficiency and to reduce the cost and time spent on the foreign trade in oligopolies, our groups have made several recommendations. The first one is a universal recommendation, while others are specially designed for the three main situations.

\section{Recommendations}

1) Avoid conflict of interest by setting a baseline within the company and mentioning the ideal agreement to the other companies; this can help companies negotiate with a precondition that they can keep their interest and it's the baseline of the win-win result is self-interest.

2) Search for background information to identify the market condition, mutual benefit and fundamental goals for both companies (cultures, abilities, market position, financial accounts, etc); they can be aware that they were not the only firms in the industry. They can know how many profits they gain from every action, which will help both companies to have a better understanding of the market and have more preparation for further negotiations.

3) Find the competitive advantages and disadvantages of the companies while having litigation. They are willing to end the litigation and have cooperation only if they each can receive benefits from each other; this will help companies achieve a win-win result by setting a compromised plan.

4) Mention that ends the litigation swiftly can be a benefit for both companies. The litigation will waste companies a lot of money and time effort and long-Term litigation will be extremely costly; this can reduce the chance of causing more harm for both companies.

5) Hire competent advisors to set an appropriate price of merger and acquisition and refer to prices posted by competitors; this will help the company gain preponderance in negotiations compared with its rivals.

The result reported here is depending on the idea that the all the companies can get the needs and the information of both companies in a proper way without spying on each other. And the actions are not against the law of preventing the monopolies from forming. The reports are depending on the ideal condition, which the cost of the research is ignorable when compared with the cost or loss when the model is simply the Cournot Model. The strategies do not mean to earn extra profit but to prevent the substantial loss when the firms are in the competition. These revenues can be counted as the essential goal both companies looking for. Moreover, in the actual world, the companies involved may be even greater than two or three firms. But to be simplified, we mainly focus on 
two firms.

Overall, cooperated with the analysis of true world event, this paper mainly provides a guide for the future direction for the business management and profit maximizing. Though the topic we discussed is mainly about the oligopolies which have some influence in the whole market, the points and suggestions can be considered to use by all the business runners in all kinds of industries and firms of any schedule. It offers the mind set of division and directions for the strategies used in the complex business condition. Only one side's succession cannot last long. Only achieving a balance and ensuring the profit for everyone, the business can grow in a even faster rate rather than waste some lump-sum cost on the disagreement within the industry.

However, all our researches are depending on the previous event, and we didn't have a chance to learn more internal details for these successful events. All we can find is from the document mentioned by the officials or the finance report. And most of our ideas are our hypothesis and conclusions. We did not make experiments for the efficiency of the strategies. We expect that we can have future first hand resource in this area and test how efficient these strategies are to maximize the profit for running a company.

\section{Conflicts of Interest}

The authors declare no conflicts of interest regarding the publication of this paper.

\section{References}

[1] Chakrabarti, S.K. (2010) Collusive Equilibrium in Cournot Oligopolies with Unknown Costs. International Economic Review, 51, 1209-1238. https://doi.org/10.1111/j.1468-2354.2010.00616.x

[2] Rajan, R. (1989) Endogenous Coalition Formation in Cooperative Oligopolies. International Economic Review, 30, 863-876. https://ideas.repec.org/a/ier/iecrev/v30y1989i4p863-76.html https://doi.org/10.2307/2526756

[3] Phelps, O.W. (1942) A Theory of Business Communication. The Journal of Business of the University of Chicago, 15, 343-360. https://doi.org/10.1086/232635

[4] Randakevičute; J. (2015) Issues Related to Standardization Leading to Litigation. In: Randakeviciuute, J., Ed., The Role of Standard-Setting Organizations with Regard to Balancing the Rights between the Owners and the Users of Standard-Essential Patents, 27-38. https://doi.org/10.5771/9783845264271-27

[5] Tsilikas, H. (2019) Standards-Setting and EU Competition Law. In: Tsilikas, H., Ed., Antitrust Enforcement and Standard Essential Patents, Nomos Verlagsgesellschaft $\mathrm{mbH}, 41-48$. https://doi.org/10.5771/9783845285191-41

[6] Li, G. (2018) Competition Policy and IPRs: Well-Functioning Symbiosis-A Case Study. In: Li, G., Ed., Revisiting China's Competition Law and Its Interaction with Intellectual Property Rights, Nomos Verlagsgesellschaft mbH, 59-72. https://doi.org/10.5771/9783845292687-59

[7] Experts, N. (2019) Negotiating with WalMart Buyers. https://www.negotiations.com/case/negotiating-wal-mart/ 
[8] Harroch, R. (2016) 15 Tactics for Successful Business Negotiations.

https://www.forbes.com/sites/allbusiness/2016/09/16/15-tactics-for-successful-busin ess-negotiations/\#5c7f91e22528

[9] Kim, E. (2017) As Amazon's Dominance Grows, Suppliers Are Forced to Play by Its Rules.

https://www.cnbc.com/2017/12/21/as-amazons-dominance-grows-suppliers-are-for ced-to-play-by-its-rules.html

[10] Jiang, S. (2019) Huawei and Samsung Agree to Settle Patent Dispute in U.S. Court. https://www.reuters.com/article/us-huawei-tech-samsung-elec-litigation/huawei-sa msung-agree-to-settle-patent-dispute-in-u-s-court-idUSKCN1QG10Y

[11] Doug, L. (2019) Samsung and Huawei Agree to Settle Dispute over Smartphone Patents.

https://www.xda-developers.com/samsung-and-huawei-agree-to-settle-dispute-over -smartphone-patents/

[12] Cadbury (2015) Our Story. https://www.cadbury.co.uk/our-story 